\title{
Erratum to: Pathways of rural change: an integrated assessment of metabolic patterns in emerging ruralities
}

\author{
F. Ravera $\cdot$ A. Scheidel $\cdot$ J. Dell' Angelo $\cdot$ G. Gamboa $\cdot$ \\ T. Serrano $\cdot$ S. Mingorría $\cdot$ V. Cabello $\cdot$ N. Arizpe $\cdot$ P. Ariza
}

Published online: 19 June 2014

(C) Springer Science+Business Media Dordrecht 2014

\section{Erratum to: Environ Dev Sustain DOI 10.1007/s10668-014-9534-9}

Unfortunately, there was a typographical error in the third author's name. It should read J. Dell' Angelo and some of the author's affiliation are listed incorrectly in the original article.

The corrected list is provided in this erratum.

The online version of the original article can be found under doi:10.1007/s10668-014-9534-9.

F. Ravera $(\bowtie)$

Social-Ecological Systems Laboratory, Department of Ecology, Universidad Autónoma de Madrid (UAM), Madrid, Spain

e-mail: federica.ravera@uam.es

A. Scheidel · J. Dell' Angelo · G. Gamboa - T. Serrano - S. Mingorría Institut de Ciència i Tecnologia Ambientals (ICTA), Universitat Autónoma de Barcelona (UAB), Cerdanyola del Vallès, Spain

J. Dell' Angelo

The Vincent and Elinor Ostrom Workshop in Political Theory and Policy Analysis, Indiana University, Bloomington, IN, USA

G. Gamboa

Building, Energy and Environment Group, International Center for Numerical Methods in Engineering (CIMNE), Polytechnic University of Catalonia (UPC), Barcelona, Spain

\section{Cabello}

Department of Human Geography, University of Seville, Seville, Spain

N. Arizpe

Programa de Postgrado de Antropología Social (PPAS), Universidad Nacional de Misiones, Posadas, Argentina

P. Ariza

Facultad Latinoamericana de Ciencias Sociales (FLACSO), Quito, Ecuador 